\title{
Reproductive System Findings Result Standard Unit
}

National Cancer Institute

\section{Source}

National Cancer Institute. Reproductive System Findings Result Standard Unit. NCI

Thesaurus. Code C117648.

The standard unit of measure for reproductive system findings results. 